\title{
Morphometric Study of Pterion in Dry Human Skull at Medical College of Eastern Nepal
}

\author{
*Umesh Kumar Mehta ${ }^{1}$, Arun Dhakal ${ }^{1}$, Surya Bahadur Parajuli ${ }^{2}$, Sanjib Kumar Sah ${ }^{1}$ \\ ${ }^{1}$ Lecturer, Department of Anatomy \\ ${ }^{2}$ Assistant Professor, Department of Community Medicine, Birat Medical College \& Teaching Hospital \\ (BMCTH), Morang, Nepal
}

\section{*Corresponding Author:}

\section{Mr. Umesh Kumar Mehta}

Contact: ukmehta32@gmail.com, ORCID: https://orcid.org/0000-0003-3095-8415

\section{ABSTRACT}

Introduction: The pterion is defined as an $\mathrm{H}$ shaped sutural confluence present on the lateral side of the skull. This pterion junction has been used as a common extra-cranial landmark for surgeons in microsurgical and surgical approaches towards important pathologies of this region.

Methods: This is an analytical cross-sectional study conducted at the Department of Anatomy, Birat Medical College \& Teaching Hospital, Tankisinuwari, Morang, Nepal. Total enumeration technique was used to collect samples where 31 dry human skulls of unknown age and sex were taken. The sutural pattern and location of the pterion were determined and measured on both sides of each skull using a digital vernier caliper.

Results: Three types of sutural patterns of pterion were observed. Among them, the Sphenoparietal type was higher in frequency. The frequency was $26(83.8 \%)$ on the right side and $24(77.4 \%)$ on the left side. The distance between the center of pterion to the midpoint of the upper border of the zygomatic arch was $3.82 \pm 0.3 \mathrm{~cm}$ on the right side and $3.8 \pm 0.29 \mathrm{~cm}$ on the left side. The distance between the center of pterion to the postero-lateral aspect of fronto-zygomatic suture was $3.02 \pm 0.23$ $\mathrm{cm}$ on the right side and $3.0 \pm 0.23 \mathrm{~cm}$ on the left side.

Conclusion: The information of the sutural pattern and the location of the pterion from the different bony landmarks of our study may be useful for anthropologists and neurosurgeons.

Keywords: Frontozygomatic suture, Morphometric, Pterion, zygomatic arch

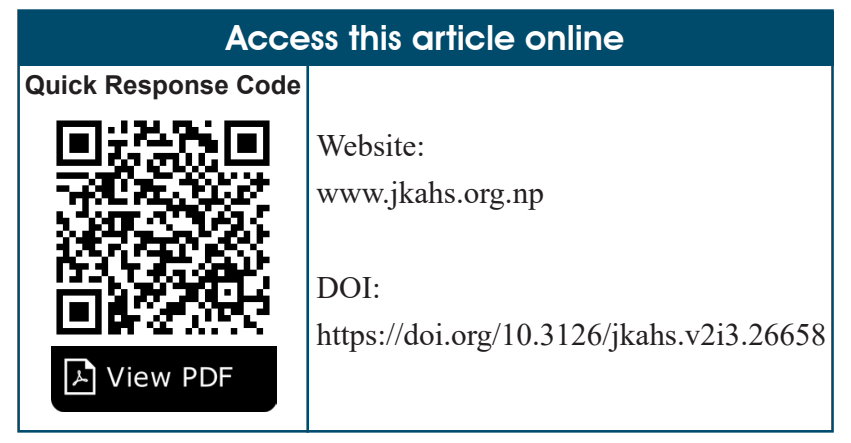

\begin{tabular}{|l|}
\multicolumn{1}{|c|}{ Article Info. } \\
\hline How to cite this article? \\
\hline $\begin{array}{l}\text { Mehta UK, Dhakal A, Parajuli SB, Sah SK. Morphometric Study of } \\
\text { Pterion in Dry Human Skull at Medical College of Eastern Nepal. } \\
\text { Journal of Karnali Academy of Health Sciences. 2019;2(3): 214-219. }\end{array}$ \\
\hline Received: 5 Oct., Accepted: 10 Nov., Published: 11 Dec. 2019 \\
\hline Conflict of Interest: None, Source of Support: None \\
\hline
\end{tabular}




\section{INTRODUCTION}

The pterion is defined as an $\mathrm{H}$ shaped sutural confluence present on the lateral side of the skull. It is formed by the association of four bones namely; frontal, parietal, squamous part of temporal and greater wing of sphenoid. It is situated approximately $4 \mathrm{~cm}$ above the midpoint of the upper border of zygomatic arch and $3.5 \mathrm{~cm}$ behind the frontozygomatic suture. ${ }^{1}$ The pterion corresponds to the site of anterolateral fontanelle of the neonatal skull which closes at third month after birth. ${ }^{2}$ Moore \& Dalley revealed that the pterion is two fingers' breadth superior to the zygomatic arch and a thumb's breadth posterior to the frontal process of the zygomatic bone. ${ }^{3}$

This pterion junction has been used as a common extra-cranial landmark for surgeons in microsurgical and surgical approaches towards important pathologies of this region. ${ }^{4}$ However this point is an essential landmark for anterior branch of the middle meningeal artery, Broca's motor speech area to the left, insula and the lateral (Sylvian) cerebral fissure. Pterional approach is the most suitable and minimally invasive approach in neuro-surgery. ${ }^{5}$ The pterion is also commonly used as an important guide for age estimation and sex determination in archeological and forensic specimens. ${ }^{6}$

The pterion shows variations in the sutural pattern of combination of constituent bones. Based on this, the pterion can be classified into different types. According to Murphy these are four types i.e. Sphenoparietal, Frontotemporal, Stellate and Epipteric. The sphenoparietal type is defined as a sutural pattern in which the sphenoid and parietal bones are in direct contact. Conversely, the frontotemporal type is a stural pattern in which the frontal and temporal bones are in direct contact. In stellate type, the four contributing bones such as frontal, parietal, sphenoid, and temporal bones articulate at a point. The fourth is of the epipteric type, which has the presence of small sutural (wormian) bone between sphenoid and parietal bones. ${ }^{7}$ These variations are of interest mainly to anthropologists and forensic pathologists. ${ }^{8}$

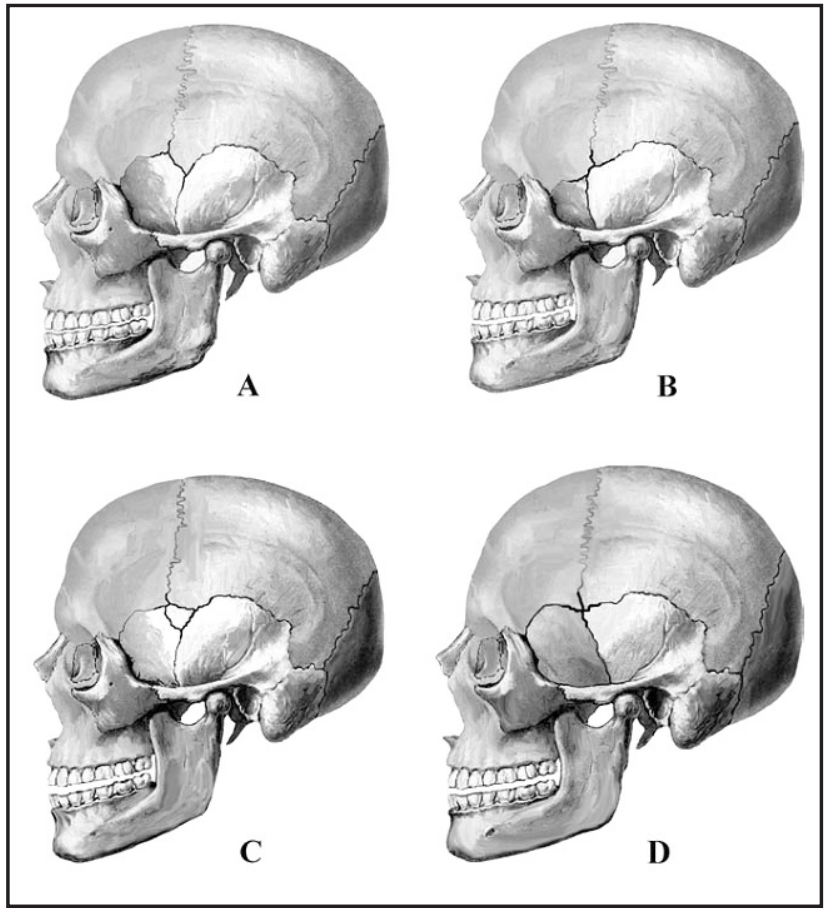

Figure 1: Murphy's classification of the shape of the pterion. ${ }^{9}$

(A) Sphenoparietal; (B) Frontotemporal; (C) Epipteric; (D) Stellate

As pterion is an important neurosurgical landmark and it exhibits variations in its sutural pattern, the objective of the present study was to determine the location of pterion (from the midpoint of the upper border of zygomatic arch \& the posterolateral aspect of the frontozygomatic fissure) and observe its sutural patterns in human dry skull.

\section{MATERIALS AND METHODS}

This is an analytical cross sectional study conducted at Department of Anatomy, Birat Medical College \& Teaching Hospital, Tankisinuwari, Morang, Nepal from July 2019 to September 2019. Total enumeration technique is used to collect samples where 31 dry human skulls of unknown age and sex were taken. Skulls exhibiting pathological changes and congenital anomalies were excluded from the study. Broken skulls and skulls with obliterated sutures due to synostosis were also excluded from the study. Ethical clearance was taken from Institutional Review Committee (IRC-PA-031/2076-77) of Birat Medical College \& Teaching Hospital, Morang, Nepal. The skulls were 
studied macroscopically to find the sutural pattern of the pterion on both the right and left sides of each skull based on descriptions (sphenoparietal, frontotemporal, stellate and epipteric types). ${ }^{7}$ For the measurement of the distance of pterion from different bony landmarks, the centre of pterion was first established by drawing a smallest circle which connected all the four bones involved in the formation of pterion. The centre of the circle was considered as the centre of pterion.

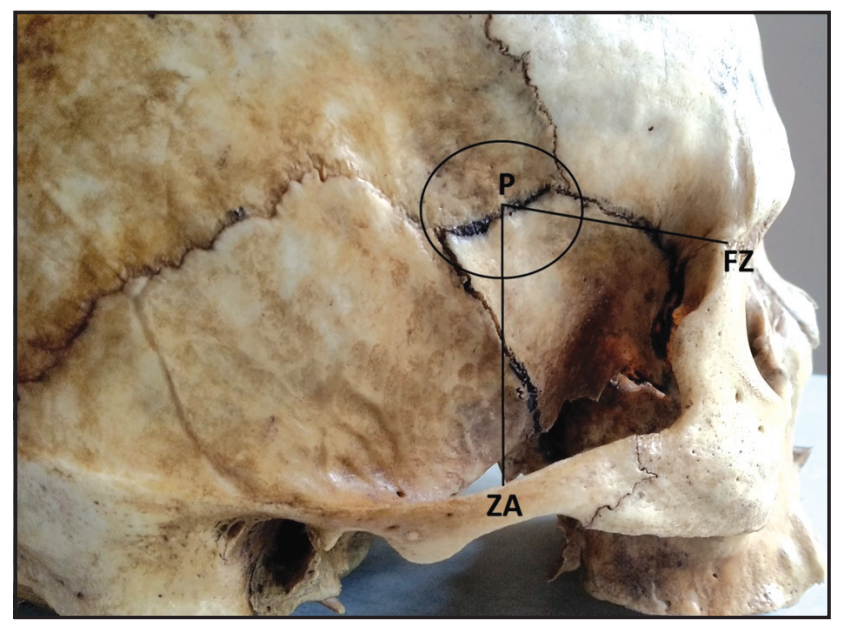

Figure 2: Measurements taken from pterion $(\mathrm{P})$ to midpoint of the upper border of zygomatic arch (ZA) and pterion to the posterolateral aspect of the frontozygomatic fissure (FZ)

We measured the distance from the center of the pterion to the midpoint of the upper border of zygomatic arch (ZA), the distance from the center of the pterion to the posterolateral aspect of the frontozygomatic fissure (FZ) (figure 2). The measurements were taken on both sides of the skull with a digital Vernier caliper with an accuracy of $0.1 \mathrm{~mm}$. The measurements were taken twice by single observer and then the average was calculated as the final measurement. All the data was tabulated according to the side of the skull and analyzed using SPSS version 23.0. The Student's t-test was employed in the assessment of side differences. $P$ value $<0.05$ was considered significant.

\section{RESULTS}

In the present study, three types of sutural patterns of pterion were observed. Sphenoparietal variety was the most common variety. The frequency was $26(83.8 \%)$ on the right side and $24(77.4 \%)$ on the left side. The frontotemporal type was observed in $3(9.6 \%)$ cases on the right side and $5(16.1 \%)$ case on the left side. Stellate type of pterion was observed in $2(6.4 \%)$ case on the right side and $2(6.4 \%)$ case on the left side. There was no epipteric type of suture present between the skulls. The frequency of different types of sutural pattern of pterion after combining both the sides is shown in Table 1.

Table 1: Showing the Frequency of different types of pterion observed on the right and left sides of the skull

\begin{tabular}{lccc}
\hline \multirow{2}{*}{$\begin{array}{c}\text { Types of } \\
\text { pterion }\end{array}$} & Right side & Left side & Both side \\
\cline { 2 - 4 } & $\mathbf{n = 3 1}$ & $\mathbf{n}=\mathbf{3 1}$ & $\mathbf{n}=\mathbf{6 2}$ \\
\hline Sphenoparietal & 26 & 24 & 50 \\
& $(83.8 \%)$ & $(77.4 \%)$ & $(80.6 \%)$ \\
Frontotemporal & $3(9.6 \%)$ & $5(16.1 \%)$ & $8(12.9 \%)$ \\
Stellate & $2(6.4 \%)$ & $2(6.4 \%)$ & $4(6.4 \%)$ \\
\hline
\end{tabular}

The distance between the centre of pterion to the midpoint of upper border of zygomatic arch (P-ZA) was $3.82 \pm 0.3 \mathrm{~cm}$ on the right side of the skull, whereas on left side of the skull it was $3.8 \pm 0.29 \mathrm{~cm}$. Distance between the centre of pterion to the postero-lateral aspect of fronto-zygomatic suture (P-FZ) on right side of the skull was $3.02 \pm 0.23 \mathrm{~cm}$ and it was $3.0 \pm 0.23 \mathrm{~cm}$ on the left side. The distances were higher on the right side than the left side. However, the side difference was not found statistically significant (table 2).

\begin{tabular}{cccc} 
Table 2: & $\begin{array}{l}\text { Mean and Standard deviations of } \\
\text { distance between center of the } \\
\text { pterion to various bony landmarks }\end{array}$ \\
\hline Parameters & $\begin{array}{c}\text { Right side } \\
\text { (mean } \pm \text { SD) } \\
\text { in } \mathbf{~ c m ~}\end{array}$ & $\begin{array}{c}\text { Left side } \\
\text { (mean } \pm \text { SD) } \\
\text { in } \mathbf{~ c m ~}\end{array}$ & p value \\
\hline P-ZA & $3.82 \pm 0.3$ & $3.8 \pm 0.29$ & 0.891 \\
P-FZ & $3.02 \pm 0.23$ & $3.0 \pm 0.23$ & 0.985
\end{tabular}

p-value $<0.05=$ statistically significant

SD: Standard deviation, P-ZA: Pterion to the midpoint of upper border of the zygomatic arch, P-FZ: Pterion to the posterolateral aspect of frontozygomatic suture 
Combining both the sides, the center of the pterion was found to be located at a distance of $3.81 \pm 0.29 \mathrm{~cm}$ from the midpoint of upper border of zygomatic arch and $3.01 \pm 0.23 \mathrm{~cm}$ from the posterolateral aspect of frontozygomatic suture. The distances measured are represented in table 3 .

\section{Table 3: Mean and Standard deviations of distance between center of the pterion to various bony landmarks of both sides}

\begin{tabular}{cc}
\hline Parameters & Both side $($ mean \pm SD) in $\mathbf{~ m ~}$ \\
\hline P-ZA & $3.81 \pm 0.29$ \\
P-FZ & $3.01 \pm 0.23$ \\
\hline
\end{tabular}

P-ZA: Pterion to the midpoint of upper border of the zygomatic arch, P-FZ: Pterion to the posterolateral aspect of frontozygomatic suture

\section{DISCUSSION}

Knowledge and understanding of the location and type of the pterion and its relation to surrounding bony landmarks are important, especially with respect to neurosurgery. In neurosurgery, it is important to approach through the most suitable bony aperture to be minimally invasive. ${ }^{5}$ Pterional approach has several advantages over traditional craniotomy that including minor tissue damage, less brain retraction, a superior cosmetic result and shorter duration of surgery. ${ }^{4}$ Hence, the knowledge of its morphological variations and location is necessary for the pterional approach used in neurosurgery.

Murphy reported in their study on Australian population that sphenoparietal type of pterion was $73 \%$, frontotemporal type of pterion $7.5 \%$, stellate type $18.5 \%$ and only $1 \%$ epipteric type of pterion. ${ }^{7}$ Oguz et al carried out a study on 26 dry Turkish adult skulls and reported that sphenoparietal type of pterion was most commonly seen (88\%), 10\% of total were frontotemporal, and $2 \%$ were epipteric. They did not find any stellate variety of pterion in their investigation. ${ }^{9}$ Mwachaka et al. observed that sphenoparietal type of pterion was higher in occurrence $(66 \%)$ and least common is epipteric type of pterion
(7\%), 15\% were frontoparietal and $12 \%$ were stellate type of pterion. ${ }^{10}$ Eboh and Obaroefe observed that sphenoparietal type of pterion is most common seen Nigerian (83\%), Fronto-temporal (5\%), Stellate (6\%) and epipteric $(6 \%) .{ }^{11}$ Matsumura et al. reported in their study on Japanese population that sphenoparietal type of pterion were $79.1 \%$, frontotemporal type of pterion were $2.6 \%$, stellate type $4 \%$ and epipteric type were $0.6 \% .{ }^{12}$ Lee et al. have reported $76.5 \%$ sphenoparietal and $23.5 \%$ epipteric type of pterions in their study involving Korean population. They could not find any frontotemporal or stellate type in their study. ${ }^{13}$ Saxena et al. studied pterion on North Indian population and reported that $87.7 \%$ sphenoparietal, $10 \%$ frontotemporal, and $2.3 \%$ stellate type of pterion. They have found no epipteric variety in their study. ${ }^{14}$ In our study we observed sphenoparietal type of pterion was the most common $80.6 \%$, whereas $12.9 \%$ and $6.4 \%$ were of frontotemporal and stellate type respectively. However we did not encounter epipteric type of pterion our study. It has been opined that the high occurrence of the sphenoparietal pterion could have an evolutionary basis. ${ }^{15}$

The pterion has been reported to lie $4 \mathrm{~cm}$ above the midpoint of the upper border of zygomatic arch and 3.0-3.5 cm behind the frontozygomatic suture. ${ }^{1}$ The present study has revealed the distance between the center of pterion and posterolateral aspect of frontozygomatic suture to be $3.02 \pm 0.23 \mathrm{~cm}$ on the right side and $3.0 \pm 0.23 \mathrm{~cm}$ on the left side. This is close to the findings of Mwachka et al. $3 \pm 0.3 \mathrm{~cm}$ right side and $3 \pm 0.4 \mathrm{~cm}$ on left side of Kenyan skulls, Apinhasmit et al.3.1 $\pm 0.4 \mathrm{~cm}$ on both sides of the skulls of Thailand and K Ephraim Vikram Rao et al. $3 \pm 0.4 \mathrm{~cm}$ and $3 \pm 0.4 \mathrm{~cm}$ right and left side of the skulls respectively in South India. ${ }^{10,16,17}$ Conversely our finding were higher than Ukohala et al. who reported that the pterion was located $2.74 \pm 0.07 \mathrm{~cm}$ posterior to the frontozygomatic suture on the right while the left was $2.74 \pm 0.06 \mathrm{~cm}$ in Nigerian skulls.18 Moreover our findings were lower than that of Oguz et al. who reported the pterion to lie $3.3 \pm 0.4 \mathrm{~cm}$ and $3.4 \pm 0.39 \mathrm{~cm}$ on right and left side respectively in Turkish skull.9 Our finding result is also lower than Sowmya $\mathrm{S}$ et al. who observed pterion was located $3.42 \mathrm{~cm}$ on right 
side and $3.33 \mathrm{~cm}$ on the left side. ${ }^{19}$ The basis for the differences could be racial, genetic or evolutionary. ${ }^{20}$

Our current study revealed that the distance between the center of pterion and the midpoint of upper border of zygomatic arch was $3.82 \pm 0.3 \mathrm{~cm}$ on the right side and $3.8 \pm 0.29 \mathrm{~cm}$ on the left side. This is close to the findings of Mwachka et al. $3.85 \pm 0.3 \mathrm{~cm}$ right side and $3.8 \pm 0.3 \mathrm{~cm}$ on left side, Apinhasmit et al. $3.84 \pm 0.4 \mathrm{~cm}$ on both sides and K Ephraim Vikram Rao et al $3.77 \pm 0.3 \mathrm{~cm}$ right side and $3.7 \pm 0.4$ left side. ${ }^{10,16,17}$ Our findings were higher than Zalawadia et al, who reported the pterion to be located $3.12 \pm 0.4$ $\mathrm{cm}$ and $2.9 \pm 0.3 \mathrm{~cm}$ superior to the midpoint of the zygomatic arch on the left and right side of the skulls respectively in Gujarat region. ${ }^{21}$

Our findings were lower than of Eboh and Obaroefe who reported the pterion to lie $4.02 \pm 0.3 \mathrm{~cm}$ right side and $3.95 \pm 0.3 \mathrm{~cm}$ left side, Ukohala et al. observed $4.03 \pm 0.05 \mathrm{~cm}$ right side and $4.01 \pm 0.03 \mathrm{~cm}$ left side of Nigerian skulls and Sowmya $\mathrm{S}$ et al. who observed pterion was located $4.02 \mathrm{~cm}$ on right side and 3.99 $\mathrm{cm}$ on the left side respectively in Indian skull. ${ }^{11,18,19}$ The variation in distance in the different studies might be because of hereditary, nutrition, geographic and environmental factors.

\section{CONCLUSIONS}

Sphenoparietal variety is the commonest type of pterion observed. The mean distance from centre of pterion to midpoint of the upper border of zygomatic arch was $3.81 \pm 0.29 \mathrm{~cm}$ and from the center of pterion to posterior aspect of the frontozygomatic suture was $3.01 \pm 0.23 \mathrm{~cm}$. These findings may be helpful for neurosurgeons and anthropologists.

\section{Acknowledgement}

We would like to acknowledge Institutional Review Committee (IRC) of Birat Medical College and Teaching Hospital for providing us permission to conduct our study. We would also like to acknowledge Mr. Surendra Kumar Sah of Department of Anatomy of Nobel Medical College and Teaching Hospital, for his valuable input, cooperation and support throughout the study period.

\section{REFERENCES}

1. Standring S. Gray's Anatomy: The Anatomical Basis of Clinical Practice. 40th ed. Edinburgh, Churchill Livingstone. 2008; 420-25.

2. Keith L Moore, T V N Persaud, Mark G Torchia. The Developing Human: Clinically Oriented Embryology 9th Edition.2011; 56-57.

3. Moore K L, Dalley A F. Clinical Oriented Anatomy.5th ed. Philadelphia, Lippincott Williams \& Wilkins. 2006; 887- 903.

4. Urzi F, Ianello A, Torrisi A, Foti P, Mortellaro NF, Cavallaro M. Morphological variability of pterion in the human skull. Ital J AnatEmbryol. 2003; 108(2):83-117.

5. Ersoy M, Evliyaoglu C, Bozkurt M, Konuskan B, Tekdemir I, Epipteric bone in the pterion may be a surgical pitfall, Minim. Invas. Neurosurg. 2003; 46(6):363-5.

6. Lovejoy CO. Meindl RS. Mensforth RP, Barton TJ. Multifactorial determination of skeletal age at death: a method a blind tests of its accuracy. Am J PhysAnthropol. 1985; 68(1):1-14.

7. Murphy, T. The pterion in the Australian aborigine. Am. J. Phys. Anthropol. 1956; 14(2):225-44.

8. Ilknur A, Mustafa KI, Sinan B. A comparative study of variation of the pterion of Human Skulls from 13th and 20th Century Anatolia. Int J Morphol 2009; 27(4):1291-1298.

9. Oguz O, Sanli SG, Bozkir MG, Soames RW. The pterion in Turkish male skulls. SurgRadiolAnat. 2004; 26:220-224.

10. Mwachaka PM, Harsanali J, Odula P. Sutural morphologyof the pterion and asterion among adult Kenyans; Braz J Morphol.Sci. 2009; 26:4-9.

11. Eboh DEO, Obaroefe M. Morphometric study of pterion in dry human skull bones of Nigerians. Int J Morphol. 2014; 32:208-213.

12. Matsumara G, Kida K, Ichikawa R, kodama G. Pterion and epipteric bones in Japanese adults and foetuses with speciel reference to 
their formation and variations. Acta Anatomica Nipponica. 1991; 66:462-471.

13. Lee UY, Park DK, Kwon SO, Paik DJ, Han SH. Morphological analysis of the pterion in Korean. Korean J PhyAnthropol. 2001; 14: 281-289.

14. Saxena RC, Bilodi AK, Mane SS, Kumar A. Study of pterion in skulls of awadh area-in and around Lucknow. Kathmandu Univ Med J (KUMJ). 2003; 1: 32-33.

15. Hussain SS, Mavishetter GF, Thomas ST, Prasanna LC, Muralidhar P, Magi. A study of sutural morphology of the pterion and asterion among human Indian skulls. Biomed Res. 2011;22:73-5.

16. Apinhasmit W, Chompoopong S, Chaisuksunt V,Thiraphatthanavong $\mathrm{P}$, Phasukdee N. Anatomical consideration of pterion and its related referencesin Thai dry skulls for pterional surgical approach. Journal Of The Medical Associaton Of Thailand Chotmaihet Thangphaet. 2011; 94(2):205-214.
17. K Ephraim Vikram Rao, B Sadananda Rao, B H Shiny Vinila. Morphology and Morphometric Analysis of Pterion with its Neurosurgical Implications in Pterional Approach. Int J Anat Res. 2017; 5(1):3384-3388.

18. Ukoha U, Oranusi CK, Okafor JI, Udemezue OO, Anyabolu AE, Nwamarachi TC. Anatomic study of the pterion in Nigerian dry human skulls. Nigerian Journal of Clinical Practice. 2013; 16(3):325-328.

19. Sowmya S, Meenakshi B, PriyaRanganath. Study of pterion: Its clinical and morphological aspects. Indian journal of Clinical Anatomy and Physiology. 2017; 4(2):247-249.

20. Ikeda T, Nakamura M \& Itoh M. Sex differences in the zygomatic angle in japanese patients analyzed by MRI with reference to Moiré fringe patterns. Aesthetic Plast. Surg. 1999; 23(5):349-53.

21. Zalawadia A, Vadgama J, Ruparelia S, Patel S, Rathod SP, Patel SV. Morphometric study of pterion in Dry Skull Gujarat Region. Njirm. 2010;1:25-9. 